\title{
FR258900, a Novel Glycogen Phosphorylase Inhibitor Isolated from Fungus No. 138354
}

\section{Taxonomy, Fermentation, Isolation and Biological Activities}

\author{
Shigetada Furukawa, Yasuhisa Tsurumi, Kana Murakami, Tomoko Nakanishi, \\ Keisuke Ohsumi, Michizane Hashimoto, Motoaki Nishikawa, Shigehiro Takase, \\ Osamu Nakayama, Motohiro Hino
}

Received: May 20, 2005 / Accepted: July 14, 2005

(C) Japan Antibiotics Research Association

\begin{abstract}
FR258900 is a novel glycogen synthesis activator produced by Fungus No. 138354. This compound was isolated from the culture broth by solvent extraction and reverse-phase column chromatography. FR258900 stimulated glycogen synthesis and glycogen synthase activity in primary rat hepatocytes. FR258900 exhibited a potent inhibitory effect on the activity of liver glycogen phosphorylase, suggesting that this compound may activate hepatic glycogen synthesis via glycogen phosphorylase inhibition. Thus, this glycogen phosphorylase inhibitor may be useful in the treatment of postprandial hyperglycemia in type 2 diabetes.
\end{abstract}

Keywords fungal metabolite, glycogen phosphorylase inhibitor, diabetes

\section{Introduction}

Type 2 diabetes is a severe and prevalent disease. Tight control of plasma glucose reduced the incidence and progression of diabetic complications, however it is difficult to achieve complete glycemic control with current oral hypoglycemic agents. The liver maintains blood glucose homeostasis by uptake of glucose in the postprandial state, and by production of glucose from glycogenolysis and gluconeogenesis in the postabsorptive state. In type 2 diabetes, the rate of glycogen synthesis is impaired, and hence hepatic glucose uptake is reduced, which results in postprandial hyperglycemia $[1,2]$. Increasing glycogen synthesis may therefore improve glucose disposal in patients with type 2 diabetes. To identify novel hypoglycemic agents, we used primary rat hepatocytes to screen various microbial products for their ability to stimulate glycogen synthesis in vitro. During the course of this screening, we discovered a novel glycogen synthesis activator FR258900, 2,3-bis(4hydroxycinnamoyloxy)glutaric acid, from the cultured broth of fungal strain No. 138354 (Fig. 1). This compound potently stimulates glycogen synthesis in primary rat

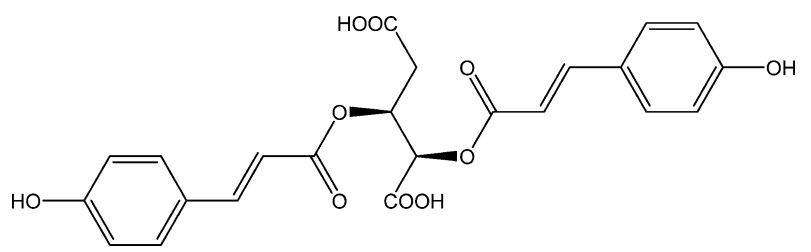

Fig. 1 Structure of FR258900
S. Furukawa (Correspondng authors), Y. Tsurumi, K. Murakami, T. Nakanishi, K. Ohsumi, M. Hashimoto, M. Hino: Fermentation Research Laboratories, Fujisawa Pharmaceutical Co., Ltd., 5-2-3 Tokodai, Tsukuba, Ibaraki 3002698, Japan, E-mail: shigetada.furukawa@jp.astellas.com

M. Nishikawa: PMD Research Center, Fujisawa Pharmaceutical Co., Ltd., 3-5-12 Hiranomachi, Chuou, Osaka 541-0046, Japan
S. Takase: Exploratory Research Laboratories, Fujisawa Pharmaceutical Co., Ltd., 5-2-3 Tokodai, Tsukuba, Ibaraki 3002698, Japan

O. Nakayama: Research Planning, Research Division, Fujisawa Pharmaceutical Co., Ltd., 2-1-6 Kashima, Yodogawa, Osaka 5320031, Japan 
hepatocytes, and exhibits a potent inhibitory effect on the activity of glycogen phosphorylase. In this paper, we describe the taxonomy of the producing microorganism, fermentation, isolation and biological activities of this compound.

\section{Materials and Methods}

\section{Taxonomy}

The producing fungus, strain No. 138354 was originally isolated from a decayed leaf, collected at Ayabe, Kyoto Prefecture, Japan. The observations were made after 14 days of cultivation at $25^{\circ} \mathrm{C}$. The compositions of malt extract agar, Czapek's solution agar and MY20 agar were based on the JCM Catalogue of Strains [3]. The color names used in this study were taken from the Methuen Handbook of Colour [4]. The temperature range of growth was determined on potato dextrose agar.

\section{HPLC Analysis}

FR258900 was detected in the fermentation broth and the fractions obtained after purification by HPLC using a reverse-phase column YMC-Pack ODS-AM 302 (150× $4.6 \mathrm{~mm}$ i.d., YMC Co., Ltd., Kyoto, Japan). The mobile phase was $30 \%$ aqueous acetonitrile containing $0.05 \%$ trifluoroacetic acid. The flow rate was $1.0 \mathrm{ml} /$ minute and the detection wavelength was set at $210 \mathrm{~nm}$.

\section{Measurement of Glycogen Synthesis}

Rat primary cultured hepatocytes were isolated by the collagenase perfusion method [5] and cultured in collagencoated 96-well plates in William's E medium supplemented with $5 \%$ fetal calf serum, 100 units $/ \mathrm{ml}$ penicillin and $100 \mu \mathrm{g} / \mathrm{ml}$ streptomycin at $37^{\circ} \mathrm{C}$ for 5 hours in a humidified atmosphere of $5 \% \mathrm{CO}_{2}-30 \% \mathrm{O}_{2}$. The cells were treated with FR258900 for 2 hours, and then washed twice with phosphate-buffered saline, and the intracellular glycogen content was measured. Glycogen levels were determined by digestion of glycogen using amyloglucosidase (Sigma, St. Louis, MO) and subsequent glucose measurement, as described previously [6].

\section{Glycogen Synthase Activity}

Glycogen synthase activity was measured as reported previously [7]. Primary rat hepatocytes were cultured in collagen-coated $90 \mathrm{~mm}$ diameter dishes, and treated with FR258900, glucagon or insulin for 2 hours. The cells were washed, and lysed in $0.5 \mathrm{ml}$ of $10 \%$ glycerol containing $50 \mathrm{mM} \mathrm{NaF}$ and $10 \mathrm{mM}$ EDTA by sonication on ice. Cell lysates were centrifuged at $15000 \times g$ for 20 minutes at $2^{\circ} \mathrm{C}$.
The supernatant were assayed for glycogen synthase activity in assay buffer ( $\mathrm{pH} 7.5)$ containing $67 \mathrm{mM}$ Tris$\mathrm{HCl}, 5 \mathrm{mM}$ DTT, $6.7 \mathrm{mM}$ EDTA, $13 \mathrm{mg} / \mathrm{ml}$ glycogen and $8.9 \mathrm{mM}\left[{ }^{14} \mathrm{C}\right] \mathrm{UDP}$-glucose $(1 \mu \mathrm{Ci} / \mu \mathrm{mol})$ with or without $10 \mathrm{mM}$ glucose-6-phosphate (G-6-P) for 20 minutes at $37^{\circ} \mathrm{C}$. The reactions were spotted on $2-\mathrm{cm}$ Whatman $3 \mathrm{MM}$ filters. Filters were washed several times in ice-cold $66 \%$ ethanol, and counted for incorporated ${ }^{14} \mathrm{C}$ radioactivity. Active glycogen synthase and total glycogen synthase were determined in the absence or presence of the allosteric activator G-6-P, respectively. Glycogen synthase activity is expressed as the activity ratio $(-\mathrm{G}-6-\mathrm{P} /+\mathrm{G}-6-\mathrm{P})$ [7]. Glycogen synthase is post-translationally modified by phosphorylation that directly inhibits the enzyme. An increase in this ratio reflects a decrease in the phosphorylation state of glycogen synthase.

\section{Assays for Key Enzymes in Glycogen Metabolism}

Glycogen phosphorylase (GP) was prepared as previously described [8], with modifications. A cDNA encoding human liver GP was subcloned into the GST expression vector pGEX-4T-2 (Amersham Biosciences Corp., Piscataway, NJ). The GST-GP fusion protein was expressed in $E$. coli $\mathrm{DH} 5 \alpha$ cells, and was purified by using the Glutathione Sepharose 4B (Amersham Biosciences Corp.). The fusion protein was cleaved by thrombin protease (Amersham Biosciences Corp.). It was then reacted with phosphorylase kinase (Sigma) to obtain the phosphorylated active form of the enzyme (GPa), and subjected to anion exchange chromatography. Glycogen phosphorylase activity was measured in the direction of glycogen synthesis by the release of inorganic phosphate from glucose-1-phosphate in a buffer containing $50 \mathrm{mM}$ Hepes (pH 7.2), $100 \mathrm{mM} \mathrm{KCl}, 2.5 \mathrm{mM}$ EGTA, $2.5 \mathrm{mM} \mathrm{MgCl}_{2}$, $0.5 \mathrm{mM}$ glucose-1-phosphate, and $1 \mathrm{mg} / \mathrm{ml}$ glycogen at $25^{\circ} \mathrm{C}$. Inorganic phosphate was measured by addition of $1 \mathrm{M} \mathrm{HCl}$ containing $10 \mathrm{mg} / \mathrm{ml}$ ammonium molybdate and $0.38 \mathrm{mg} / \mathrm{ml}$ malachite green, and the absorbance was determined at $620 \mathrm{~nm}$ [9]. Glycogen synthase kinase-3 (GSK-3) activity was measured according to the method described by Coghlan et al. [7] using recombinant GSK-3 $\beta$ (Sigma) and phospho GS-2 peptide (Upstate Biotechnology, Lake Placid, NY) as a substrate. Glucose-6phosphatase (G-6-Pase) activity was assayed according to the method described previously [10]. We used rat liver microsomes as the source of G-6-Pase. Protein tyrosine phosphatase-1B (PTP1B) activity was measured using a kit (Calbiochem, San Diego, CA). 


\section{Results}

\section{Characteristics of the Producing Strain}

Cultural characteristics on various agar media are summarized in Table 1. This microorganism grew very restrictedly and formed dark grayish colonies on various agar media. Culture on potato dextrose agar grew very restrictedly, attaining $1.0 \sim 2.0 \mathrm{~cm}$ in diameter two weeks later at $25^{\circ} \mathrm{C}$. The colony surface was raised, felty to cottony, wrinkly, and olive gray. The reverse was dark green. Colonies on corn meal agar grew at a similar rate as on potato dextrose agar, attaining $1.0 \sim 2.0 \mathrm{~cm}$ in diameter under the same conditions. The surface was plane, felty, olive and brownish gray at the center. The reverse was olive. This strain was able to grow at the temperature range from 5 to $28^{\circ} \mathrm{C}$, with the growth optimum at 21 to $22^{\circ} \mathrm{C}$.

Strain No. 138354 formed neither teleomorph nor anamorph. Hyphae sometimes aggregated to a spherical mass like a pycnidium or a pericethium in old cultures, especially on corn meal agar. The aggregations were dark brown, globose to ellipsoidal, non-ostiolate, and did not produce spores. Their size was $40 \sim 90 \times 35 \sim 70 \mu \mathrm{m}$ with a length:breadth ratio of $1.0 \sim 1.4$. Vegetative hyphae were brown, smooth, septate and branched. The hyphal cells were cylindrical and $2 \sim 5.5 \mu \mathrm{m}$ thick. Chlamydospores were absent.

The above characteristics of the producing strain No. 138354 were insufficient for fungal identification, thus the strain was named simply as "Fungus No. 138354".

\section{Fermentation}

A loopful of fungus strain No. 138354 was inoculated from a slant culture into two $500 \mathrm{ml}$-Erlenmeyer flasks each containing $100 \mathrm{ml}$ of the seed medium consisting of corn starch $2 \%$, glycerin $1 \%$, sucrose $1 \%$, Pharmamedia $1 \%$, gluten meal $1 \%$, tween $800.2 \%$. The flasks were incubated at $25^{\circ} \mathrm{C}$ for 6 days on a rotary shaker $(220 \mathrm{rpm})$. The resultant seed culture was inoculated into 20 liters of sterilized production medium in a 30-liter jar fermentor. The production medium was composed of soluble starch $6 \%$, glucose $2 \%, \mathrm{KCl} 0.02 \%, \mathrm{MgSO}_{4} \cdot 7 \mathrm{H}_{2} \mathrm{O} \quad 0.02 \%$, $\mathrm{KH}_{2} \mathrm{PO}_{4} 0.1 \%, \beta$-cyclodextrin $1 \%$, yeast extract $0.25 \%$, Adekanol LG-109 (Asahi Denka Co., Ltd., Tokyo, Japan)

Table 1 Cultural characteristics of strain No.138354

\begin{tabular}{|c|c|}
\hline Media & Cultural characteristics \\
\hline Malt extract agar & $\begin{array}{l}\text { G: Very restrictedly, } 1.0 \sim 2.0 \mathrm{~cm} \\
\text { S: Circular, plane, felty to cottony, sectoring, greenish gray (30C2 30E2) } \\
\text { R: Dark green (28F4) }\end{array}$ \\
\hline $\begin{array}{l}\text { Potato dextrose agar } \\
\text { (Difco 0013) }\end{array}$ & $\begin{array}{l}\text { G: Very restrictedly, } 1.0 \sim 2.0 \mathrm{~cm} \\
\text { S: Circular, raised, felty to cottony, wrinkly, olive gray (1E2) } \\
\text { R: Dark green }(27 F 3 \sim 27 F 4)\end{array}$ \\
\hline Czapek's solution agar & $\begin{array}{l}\text { G: Very restrictedly, } 0.5 \sim 1.5 \mathrm{~cm} \\
\text { S: Circular, submerged, plane, felty, dark green (27F3) } \\
\text { R: Dark green (27F3) }\end{array}$ \\
\hline $\begin{array}{l}\text { Sabouraud dextrose agar } \\
\text { (Difco 0190) }\end{array}$ & $\begin{array}{l}\text { G: Very restrictedly, } 1.0 \sim 2.0 \mathrm{~cm} \\
\text { S: Circular, raised to capitate, felty, radiately sulcate, brownish gray (4D2) } \\
\text { R: Dark green (27F3) }\end{array}$ \\
\hline $\begin{array}{l}\text { Emerson Yp Ss agar } \\
\qquad \text { (Difco 0739) }\end{array}$ & $\begin{array}{l}\text { G: Very restrictedly, } 0.5 \sim 1.5 \mathrm{~cm} \\
\text { S: Circular, plane, felty, love brown (4E3 4F3) } \\
\text { R: Dark green (28F4) }\end{array}$ \\
\hline $\begin{array}{l}\text { Corn meal agar } \\
\text { (Difco 0386) }\end{array}$ & $\begin{array}{l}\text { G: Very restrictedly, } 1.0 \sim 2.0 \mathrm{~cm} \\
\text { S: Circular, plane, felty, olive (2F3), brownish gray }(4 \mathrm{C} 2) \text { at center } \\
\text { R: Olive (2F3) }\end{array}$ \\
\hline MY20 agar & $\begin{array}{l}\text { G: Very restrictedly, } 1.0 \sim 2.0 \mathrm{~cm} \\
\text { S: Circular, plane to raised, felty to cottony, radiately sulcate, brownish gray (4E2 } \sim 5 \mathrm{E} 2) \text { to gray (1E1) } \\
\text { R: Dark green (28F3 } 28 \mathrm{~F} 4)\end{array}$ \\
\hline $\begin{array}{l}\text { Oatmeal agar } \\
\text { (Difco 0386) }\end{array}$ & $\begin{array}{l}\text { G: Very restrictedly, } 1.0 \sim 2.0 \mathrm{~cm} \\
\text { S: Circular, plane to raised, felty, gray }(1 \mathrm{D} 1 \sim 1 \mathrm{E} 1) \text {, olive gray }(2 \mathrm{~F} 2) \text { to olive }(2 \mathrm{~F} 3) \text { at margin }\end{array}$ \\
\hline
\end{tabular}

Abbreviation: G, growth measured by colony size in diameter; $\mathrm{S}$, colony surface; $\mathrm{R}$, reverse. 
0.05\%, and Silicone KM-70 (ShinEtsu Chemical Co., Ltd, Tokyo, Japan) $0.05 \%$. The $\mathrm{pH}$ of the medium was adjusted to 6.5 before sterilization. Fermentation was carried out at $25^{\circ} \mathrm{C}$ for 6 days at an aeration rate of 20 liters/minute and agitation speed of $200 \mathrm{rpm}$. The amount of FR258900 in the fermentation broth reached about $95 \mu \mathrm{g} / \mathrm{ml}$ at 6 days.

\section{Isolation and Purification}

After the culture was completed, the culture broth was filtered with the aid of diatomaceous earth. The mycelial cake was extracted with 20 liters of acetone by stirring for an hour at room temperature. The extract was filtered with the aid of diatomaceous earth. The filtrate was evaporated to remove acetone and the resultant aqueous layer was extracted with ethyl acetate twice at $\mathrm{pH}$ 2.0. The organic layer was concentrated in vacuo to give a brown extract. The extract was dissolved in $50 \mathrm{ml}$ of methanol and promptly passed through a column (2 liters) of Daisogel SP-120-ODS-B (15/30 $\mu \mathrm{m}$, Daiso Co., Ltd., Osaka, Japan) packed with water containing $0.05 \%$ TFA. The column was eluted with $30 \%$ aqueous acetonitrile containing $0.05 \%$ TFA (6 liters). The elution was monitored by analytical HPLC as described in Material and Methods. The retention time of FR258900 was 8.5 minutes. The portion corresponding to FR258900 was evaporated to remove acetonitrile and the resultant aqueous layer was extracted with ethyl acetate twice. The organic layer was dried over $\mathrm{Na}_{2} \mathrm{SO}_{4}$ and concentrated in vacuo to give an oily residue. This material was dissolved in a small amount of diethyl ether and concentrated to give a powder. The powder was dissolved in a small amount of hot water $\left(70^{\circ} \mathrm{C}\right)$ and cooled to give crystals. The crystals were filtered and dried to give $1 \mathrm{~g}$ of FR258900.

\section{Physico-chemical Properties}

As shown in Table 2, FR258900 was soluble in methanol, acetonitrile, ethyl acetate and dimethyl sulfoxide, slightly soluble in water, and insoluble in $n$-hexane. The compound showed positive color reactions to iodine vapor, though negative against Morich, Ehrlich, $\mathrm{FeCl}_{3}$, Dragendorf and ninhydrin, and showed UV absorption at 227 and $310 \mathrm{~nm}$. The determination of the structure of FR258900 was accomplished primarily by a series of 2-D NMR techniques. Total synthesis of FR258900 was achieved, and the absolute configuration was determined as Fig 1. The details of the structure elucidation studies of FR258900 will be described elsewhere.

\section{Biological Activities}

FR258900 stimulated glycogen synthesis in primary rat hepatocytes in a dose dependent manner (Fig. 2a). We
Table 2 Physico-chemical properties of FR258900

\begin{tabular}{ll}
\multicolumn{1}{c}{ Properties } & \multicolumn{1}{c}{ FR258900 } \\
\hline Appearance & White crystal \\
Molecular formula & $\mathrm{C}_{23} \mathrm{H}_{20} \mathrm{O}_{10}$ \\
Molecular weight & 456 \\
HRESI-MS $(\mathrm{m} / z)$ & \\
Found $(\mathrm{M}+\mathrm{H})^{+}$ & 457.1148 \\
Calcd. $(\mathrm{M}+\mathrm{H})^{+}$ & 457.1134 \\
{$[\alpha]_{D}^{25}$} & $-216(\mathrm{c}=0.21, \mathrm{MeOH})$ \\
m.p. & $212 \sim 214{ }^{\circ} \mathrm{C}$ \\
UV $\lambda_{\text {max }}^{\text {MeOH }} \mathrm{nm}(\varepsilon)$ & $227(26100), 310(51200)$ \\
Solubility & \\
Soluble & MeOH, acetonitrile, EtOAc \\
& DMSO \\
Slightly soluble & Water \\
Insoluble & $n$-Hexane \\
TLC Rf & 0.23 \\
\hline
\end{tabular}

${ }^{a}$ Silicagel $60 \mathrm{~F}_{254}$ (E. Merck), $n$-butanol : ethanol : ammonia=1:1:1.

a

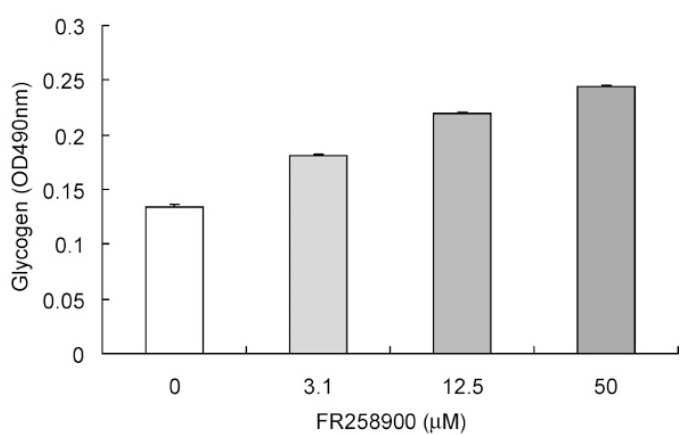

b

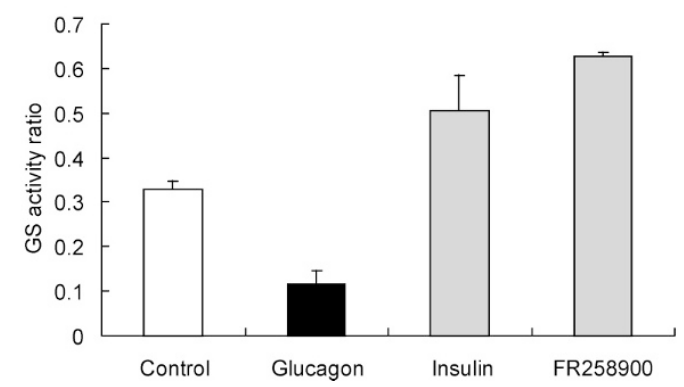

Fig. 2 Effects of FR258900 on glycogen synthesis in rat primary hepatocytes. (a) The intracellular glycogen content of primary cultured hepatocytes treated with the indicated concentrations of FR258900 for 2 hours. The data are displayed as means \pm S.E.M. of glucose concentration equivalent of glycogen $(n=6)$. (b) Glycogen synthase activity in the hepatocytes treated with $30 \mathrm{nM}$ glucagon, $1 \mu \mathrm{M}$ insulin or $10 \mu \mathrm{M}$ FR258900. The data are displayed as means \pm S.E.M. of GS activity ratio calculated as described in the Materials and Methods $(n=3)$. 
Table 3 Inhibitory effects of FR258900 on various enzyme activities

\begin{tabular}{lc}
\hline \multicolumn{1}{c}{ Enzyme } & $\mathrm{IC}_{50}(\mu \mathrm{M})$ \\
\hline Glycogen phosphorylase & 2.5 \\
Glucose-6-phosphatase & $>200$ \\
Glycogen synthase kinase-3 & $>200$ \\
Protein tyrosine phosphatase 1B & $>200$ \\
\hline
\end{tabular}

examined whether the ability of FR258900 to stimulate glycogen synthesis resulted from activation of glycogen synthase, the rate-determining enzyme in glycogen synthesis. As shown in Fig. 2b, glucagon suppressed glycogen synthase activity. In contrast, FR258900 stimulated glycogen synthase activity as well as insulin. To determine the target molecule of FR258900, we examined the ability of FR258900 to inhibit key enzymes in glycogen metabolism [11]. Glycogen phosphorylase catalyzes the first step in glycogen degradation. G-6-Pase catalyzes the terminal reaction of glycogenolysis. GSK-3 is reported to play an important role in the regulation of glycogen synthesis via inhibitory phosphorylation of glycogen synthase [12], and PTP1B is implicated as a negative regulator of insulin signaling [13]. As shown in Table 3, FR258900 inhibited glycogen phosphorylase with $\mathrm{IC}_{50}$ of $2.5 \mu \mathrm{M}$. In contrast, FR258900 exhibited no inhibition of other enzymes, such as GSK-3, G-6-Pase, or PTP1B.

\section{Discussion}

Defects in insulin-stimulated glycogen synthesis are a major contributor to postprandial hyperglycemia in patients with type 2 diabetes. In the current study, we presented a novel fungal product FR258900 as an activator of hepatic glycogen synthesis. We also demonstrated the ability of FR258900 to stimulate glycogen synthase activity. We speculate that the activity of FR258900 to stimulate glycogen synthesis may be due to glycogen phosphorylase inhibition, because results on several chemical derivatives of FR258900 showed a correlation between upregulatory activities of glycogen synthesis and inhibitory activities of glycogen phosphorylase (data not shown). These results suggest that glycogen phosphorylase is a potential candidate target for controlling postprandial hyperglycemia in type 2 diabetes.

Glycogen phosphorylase activity is regulated by allosteric mechanisms and by phosphorylation [14]. The dephosphorylated form $(\mathrm{GPb})$ is less active than the phosphorylated form (GPa). GPa is a potent inhibitor of PP1G (glycogen targeted protein phosphatase-1) which dephosphorylates and activates glycogen synthase [15]. Therefore, FR258900 may restore PP1G activity from GPamediated inhibition, resulting in the indirect activation of glycogen synthase.

Glycogen phosphorylase is the rate-controlling enzyme of the glycogenolytic pathway [14], hence the inhibition of glycogen phosphorylase could suppress glycogenolysis and hepatic glucose output. Thus, inhibition of glycogenolysis, as well as activation of glycogen synthesis, may be also involved in increased glycogen content in hepatocytes treated with FR258900. Several inhibitors of glycogen phosphorylase described recently have demonstrated glucose-lowering effects by inhibiting hepatic glucose produciton in type 2 diabetes $[9,16]$. In the present study, we demonstrated that glycogen phosphorylase inhibitor could activate glycogen synthesis, suggesting that phosphorylase inhibitors should also be effective in promoting hepatic glycogen synthesis in the absorptive state. We describe in our accompanying paper1 [7] whether FR258900 can improve oral glucose disposal by increasing liver glycogen synthesis, and also lower blood glucose by reducing hepatic glucose output in diabetic animal models.

Acknowledgement We are grateful to Minoru Yasuda and Kentaro Sato for assistance in the preparation of this manuscript.

\section{References}

1. DeFronzo RA, Bonadonna RC, Ferrannini E. Pathogenesis of NIDDM. A balanced overview. Diabetes Care 15: 318368 (1992)

2. Consoli A. Predominant role of gluconeogenesis in increased hepatic glucose production in NIDDM. Diabetes Care 15: 430-441 (1992)

3. Nakase T. JCM Catalogue of Strains, 6th edition. Japan Collection of Microorganisms, the Institute of Physical and Chemical Research (RIKEN), Toppan (1995)

4. Kornerup A, Wanscher JH. Methuen Handbook of Colour, 3rd edition. Methuen, London (1978)

5. Seglen PO. Preparation of isolated rat liver cells. Methods Cell Biol 13: 29-83 (1976)

6. Gómez-Lechón MJ, Ponsoda X, Castell JV. A microassay for measuring glycogen in 96-well-cultured cells. Anal Biochem 236: 296-301 (1996)

7. Coghlan MP, Culbert AA, Cross DA, Corcoran SL, Yates JW, Pearce NJ, Rausch OL, Murphy GJ, Carter PS, Roxbee Cox L, Mills D, Brown MJ, Haigh D, Ward RW, Smith DG, Murray KJ, Reith AD, Holder JC. Selective small molecule inhibitors of glycogen synthase kinase-3 modulate glycogen metabolism and gene transcription. Chem Biol 7: 793-803 
(2000)

8. Coats WS, Browner MF, Fletterick RF, Newgard CB. An engineered liver glycogen phosphorylase with AMP allosteric activation. J Biol Chem 266: 16113-16119 (1991)

9. Martin WH, Hoover DJ, Armento SJ, Stock IA, McPherson RK, Danley DE, Stevenson RW, Barrett EJ, Treadway JL. Discovery of a human liver glycogen phosphorylase inhibitor that lowers blood glucose in vivo. Proc Natl Acad Sci USA 95: 1776-1781 (1998)

10. Swanson MA. Glucose-6-phosphatase from liver. Methods Enzymol 2: 541-543 (1955)

11. Radziuk J, Pye S. Hepatic glucose uptake, gluconeogenesis and the regulation of glycogen synthesis. Diabetes Metab Res Rev 17: 250-272 (2001)

12. Cohen P, Goedert M. GSK3 inhibitors: Development and therapeutic potential. Nat Rev Drug Discov 3: 479-487 (2004)

13. Elchebly M, Payette P, Michaliszyn E, Cromlish W, Collins S, Loy AL, Normandin D, Cheng A, Himms-Hagen J, Chan CC, Ramachandran C, Gresser MJ, Tremblay ML, Kennedy BP. Increased insulin sensitivity and obesity resistance in mice lacking the protein tyrosine phosphatase-1B gene. Science 283: 1544-1548 (1999)

14. Bollen M, Keppens S, Stalmans W. Specific features of glycogen metabolism in the liver. Biochem J 336: 19-31 (1998)

15. Aiston S, Hampson L, Gómez-Foix AM, Guinovart JJ, Agius L. Hepatic glycogen synthesis is highly sensitive to phosphorylase activity. J Biol Chem 276: 23858-23866 (2001)

16. Fosgerau K, Westergaard N, Quistorff B, Grunnet N, Kristiansen $\mathrm{M}$, Lundgren $\mathrm{K}$. Kinetic and functional characterization of 1,4-dideoxy-1,4-imino-D-arabinitol: A potent inhibitor of glycogen phosphorylase with antihyperglyceamic effect in ob/ob mice. Arch Biochem Biophys 380: 274-284 (2000)

17. Furukawa S, Murakami K, Nishikawa M, Nakayama O, Hino M. FR258900, a novel glycogen phosphorylase inhibitor isolated from fungus No. 138354. II. Antihyperglycemic effects in diabetic animal models. J Antibiot 58: 503-506 (2005) 